\title{
RETROSPECTIVE DATA REVIEW TO FIND THE ASSOCIATION OF LUMBOSACRAL TRANSITIONAL VERTEBRA AND DEGENERATIVE DISC DISEASE IN YOUNG PATIENTS
}

\author{
Nadia Gul, Khalid Mehmood*, Muhammad Ikram \\ POF Hospital, Wah Cantt Pakistan, *Combined Military Hospital/National University of Medical Sciences (NUMS) Rawalpindi Pakistan
}

\begin{abstract}
Objective: To find out the frequency of lumbar disc degeneration among the patients having lumbosacral transitional vertebra between $20-40$ years.

Study Design: Retrospective cross sectional study.

Place and Duration of Study: Radiology department POF Wah Cantt, from Jan 2018 to Dec 2019.

Methodology: Six Hundred patients between 20-40 years having lumbosacral transitional vertebra and history of low back pain $>1$ year were studied. $X$ ray and MRI lumbar spine of these patients was studied retrospectively on PACS. Two hundred patients having history of traumatic or other non-traumatic etiologies, in addition to Lumbosacral transitional vertebra were excluded. Four hundred patients with only lumbosacral transitional vertebra were included. Data analysis was done by SPSS-22. Castellvi types of transitional vertebra was calculated among patients with degenerative lumbar disc.

Results: One hundred and four (26.6\%) were having degenerative disc disease while 296 (74.4\%) patients were not having degenerative disc disease. Patients having degenerative disc disease were between $24-40$ years with the mean age $29.96 \pm 0.417$ years. Among the patients having degenerative disc disease were 59 women and 45 males but no statistical significance association was found between gender and degenerative disc disease with $p$-value $=0.55$. Castellvi type III had significant association with degenerative disc disease, $p$-value $=0.006$.

Conclusion: Age related disc degeneration is commonly seen in middle age people but in younger age group in $2^{\text {nd }}$ and $3^{\text {rd }}$ decade it is observed frequently in those patients having lumbosacral transitional vertebra especially in the setting of no other associated traumatic or non-traumatic etiology, which leads to early degenerative disc disease.
\end{abstract}

Keywords: Degenerative disc disease, Lumbosacral transitional vertebra, Picture archiving and communication system.

This is an Open Access article distributed under the terms of the Creative Commons Attribution License (http://creativecommons.org/licenses/by/4.0), which permits unrestricted use, distribution, and reproduction in any medium, provided the original work is properly cited.

\section{INTRODUCTION}

Lumbosacral transitional vertebra (LSTV) is a frequently observed congenital anomaly of the spine. It is associated with mutations in the Hox genes, resulting in sacralization (assimilation of L5 with sacrum or iliac crest) or lumbarization (lumbar configuration of S1 with rudimentary disc between L5-S1). It was first described by in 19171. Sacralized or lumbarized LSTV may or may not be associated with dysplastic transverse process unilaterally or bilaterally. Different studies show prevalence of LSTV ranging from $4 \%$ to $35 \%$ among different populations ${ }^{2}$. It may or may not be associated with lower back pain

Correspondence: Dr Nadia Gul, Department of Radiology, POF Hospital, Wah Cantt, Pakistan

Received: 11 Mar 2020; revised received: 30 Jul 2020; accepted: 03 Aug 2020 depending upon the type of LSTV as per Castellvi classification system. In addition type 0 is also documented in some literatures for completely lumbarized first sacral vertebra (L6) which has completely identical configuration to lumbar vertebra but has normal transverse processes. These patients are usually asymptomatic. Symptomatic patients usually present between $2^{\text {nd }}$ and $3^{\text {rd }}$ decade of life and usually have one of the four Castellvi types. There is limited movement, altered dynamics of lumbar spine and pseudoarthrosis of dysplastic tranasverse process of transitional vertebra with sacrum or iliac crest $^{3}$. Prolonged stress over time results in disc degeneration just above the level of transitional vertebra leading to nerve root compression and sciatica. Dysplastic transverse process also causes extra foraminal nerve 
root compression laterally ${ }^{4}$. Increased stress on quadratus lumborum and iliopsoas muscle causing altered lumbar spine curvature due to muscle spasm resulting in scoliosis on AP/Lat view and straightening with loss of lumbar lordosis on lateral view of $X$ ray lumbar spine.

Different radiological modalities can be used to identify LSTV including X-ray, CT-scan and $\mathrm{MRI}^{5}$. For the purpose of enumeration X-ray lumbosacral spine (AP and Lateral view) and cervicodorsal spine AP/Lat view is done to mark $\mathrm{C} 2$ vertebra and then counting is done downwards to find whether LSTV is lumbarized S1 or sacralized L5. Lateral view lumbar radiograph shows squaring of LSTV (fig-1).

CT is also a good modality for imaging of bones but when it is used for the identification of LSTV, whole spine should be imaged for enumeration which lead to a lot of radiation burden.

MRI is the best modality for evaluation of degenerative disc disease and nerve root compression. MRI can be used for the purpose of enumeration and identification of transitional vertebra but it is very time consuming. Certainly best image resolution of bone, disc and soft tissues can be achieved with MRI. So, it is a better practice to do vertebral enumeration and identification of LSTV with X-ray followed by MRI lumbosacral spine to see degenerative changes of spine and $\operatorname{discs}(\text { fig- } 2)^{6}$.

Correct identification of LSTV (lumbarization or sacralization) along with further categorization of types is very important for proper patient management. On the morphological basis Castellvi et al in 1984 devised a radiological classification system and 4 types were identified as followed.

Type-I LSTV: There is dysplastic transverse processes (elongated and broadened with vertical height measuring $19 \mathrm{~mm}$ ) either unilateral or bilateral. If unilateral it is type-1A, if bilateral it is type-1B.

Type-II LSTV: Dysplastic transverse process shows pseudoarthrosis with sacrum or iliac crest.
If unilaterally it is type II A, if bilaterally it is type II B.

Type-III LSTV: There is fusion of dysplastic transverse process with sacrum or iliac bone, if unilaterally it is III A, if bilaterally it is type III B. There is complete sacralization or lumbarization in type III B.

Type-IV LSTV: There is pseudoarthrosis of dysplastic transverse process with incomplete fusion on one side (type II) and complete fusion on other side (type III) (fig-3) 6,7.

MRI can better describe the extent of disc degeneration and can identify diffuse disc bulge, disc protrusion and disc extrusion. Also it gives better delineation of spinal canal diameter, ligamentum flavum hypertrophy and facet joint arthropathy. Degenerative disc shows disc desication with loss of its normal T2W and STIR hyperintense signal (fig- 4$)^{7,8}$.

Stress related inflammatory changes at the site of pseudoarthrosis or abnormal fusion at lumbosacral junction can be depicted on MRI as edema signal which appears hyperintense on T2W and STIR $8,9,10$.

Rationale to find cause effect relation between LSTV and degenerative disc disease is due to the fact that many young patients come with the request of X-ray lumbar spine and MRI lumbar spine, having complaint of continuous low back pain. Early disc degeneration is frequently observed among these patients with no significant etiological factor in many patients. Such young patients with discogenic pain when get scrutinized to find out the cause, usually show presence of LSTV in many cases, which is missed initially. So it is essential to look for the presence of LSTV in such patients ${ }^{10,11 .}$

\section{METHODOLOGY}

This is a cross sectional descriptive study conducted in Radiology department POF hospital Wah Cantt, from January 2018 to December 2019. Informed consent was taken from all patients undergoing radiological examinations as a part of departmental SOP. Approval from ethicsl commi- 
ttee of POF hospital was taken to use the data of PACS for this research. Sample size was 600, consisted of patients having LSTV and history of low back pain for the last 1 year. Two hundred patients having any recent or old spinal trauma, spinal infection, inflammation, and previous surgery were excluded. Rest of 400 with LSTV and low back pain were included in the study. Patients with radiological evidence of paraspinal muscle spasm or history of neurological deficits (motor/sensory/reflex) were also included. $X$ ray lumbar spine with $\mathrm{AP} /$ lat view and $\mathrm{X}$ ray cervicodorsal spine $\mathrm{AP} /$ lat view was studied to do exact enumeration of vertebrae from $\mathrm{C} 2$ downwards and to find whether lumbosacral transitional vertebra was the result of sacralization of L5 or lumbarization of S1. The type of LSTV was further categorized by Castellvi classification system in to four types. AP view of lumbosacral radiograph was used to measure enlarged transverse process unilaterally or bilaterally, maximum measured up to $19 \mathrm{~mm}$ in vertical height at the junction of middle and lateral third of transverse process / es. Lateral view of lumbosacral spine in standing position was used for the calculation of disc height. MRI sagittal view was used to assess the disc height. It was measured as the average of the sum of the craniocaudal distance between the anterior, middle, and posterior disc spaces superior and inferior to LSTV respectively, except for type $3 \mathrm{~b}$ where there is bilateral complete fusion of sacro-transverse joint and only there is a rudi-
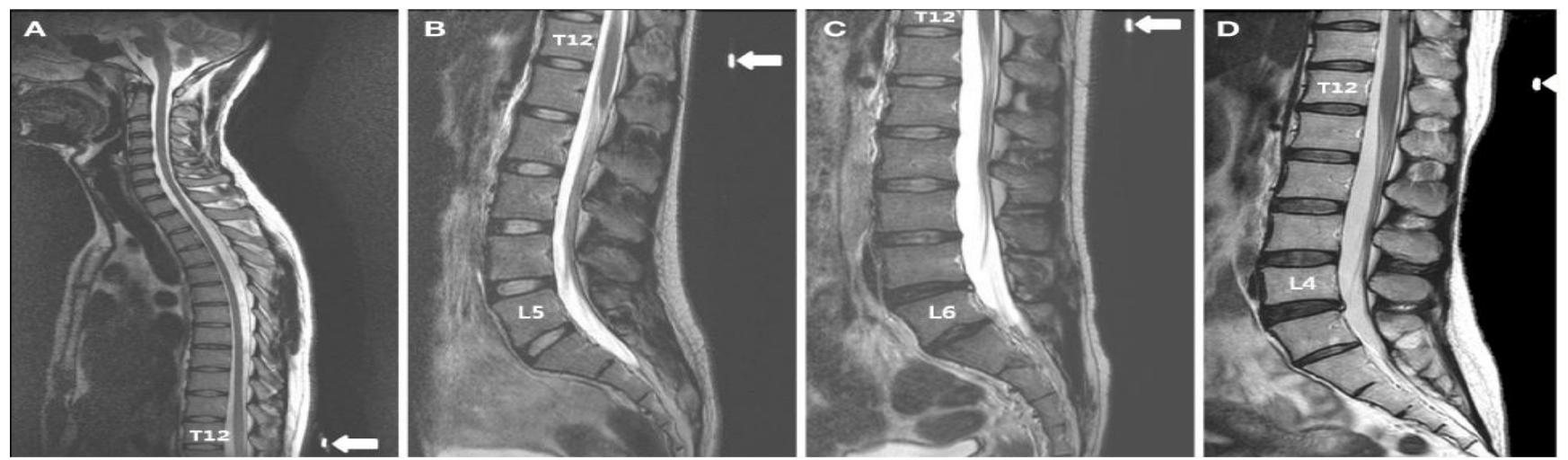

Figure-2: Enumeration of lumbosacral vertebrae by MRI (A) MRI cervicothoracic spine to localize T12 vertebral body. (B,C,D) MRI thoracolumbar spine to count lumbar vertebrae. (B) 5 lumbar vertebrae (normal). (C) 6 lumbar vertebrae (lumbarization). (D) 4 lumbar vertebrae (sacralization). 
(95\% CI 29.9 to 30). The patients having no degenerative disc disease were relatively young between $20-24$ years with mean $22 \pm 1.5$ years $(95 \%$

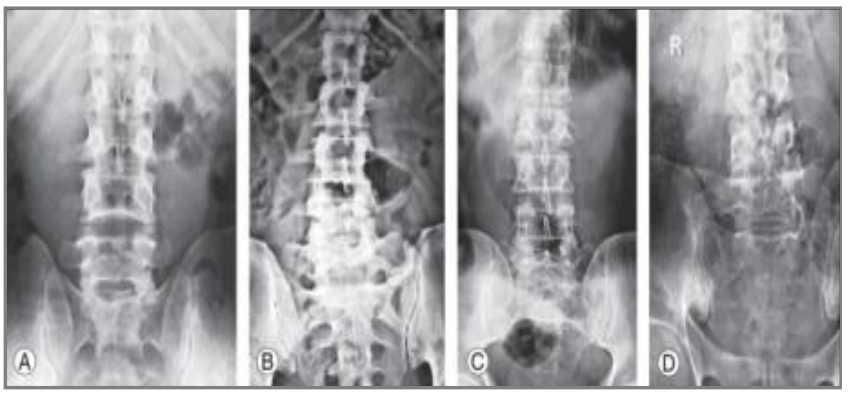

Figure-3: Castellvi LSTV (A) Type 1b (B) Type 2b(C)

Type 3b (D) Type 4.

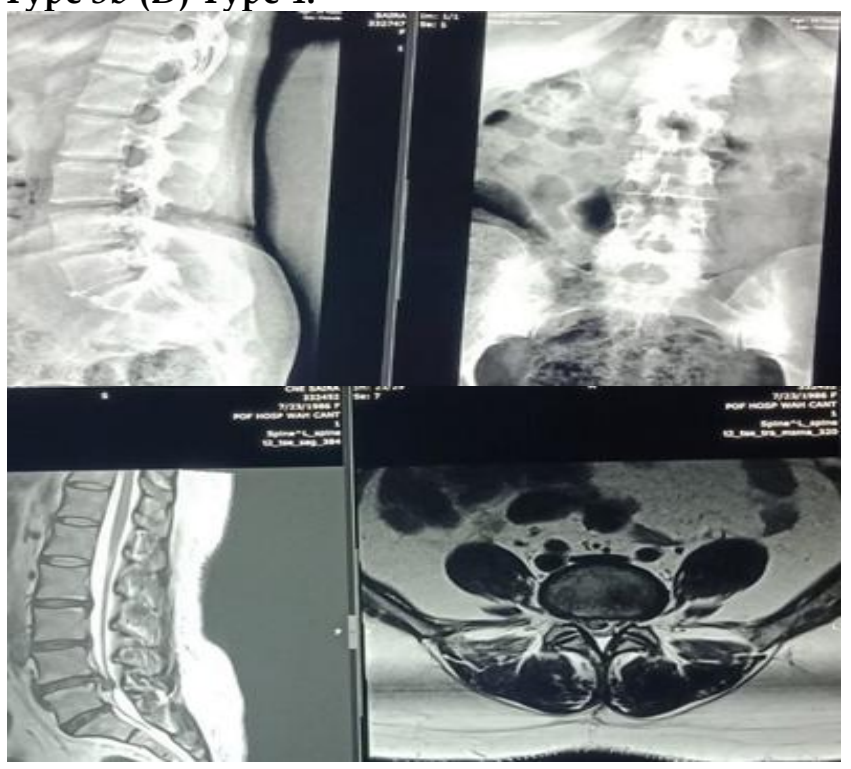

Figure-4: Lumbarization on AP X-Ray. MRI T2W sagittal section shows Disc degeneration and modic changes. MRI T2W Axial Image shows broad based Disc Herniation.

CI 21.8 to 22.). Both group with and without degenerative disc disease were showing female pre- were females and 106 were males. There was no statistical significance found between gender distribution and degenerative disc disease with $p$ value $=0.6$ and chi square $=0.331$. In 104 patients with disc herniation sacralization of L5 was more frequently observed (70/104, 67.3\%) while lumbarization of S1 was relatively less (33/104, 32.7\%). L4-5 disc level showed disc degeneration in cases with sacralization and L5-L6 was involved in lumbarization. Among the group of patients with LSTV and degenerative disc disease Castellvi Type III had significant association with degenerative disc disease with $p$-value $=0.006$ and chi square $=12.373$. This is suggestive of the fact that overall degenerative disc disease has no significant association with gender but females having Castellvi type III LSTV are more prone to develop early degenerative disc disease as compared to males.

\section{DISCUSSION}

There are multiple studies on the types of LSTV and associated changes on lumbar curvature, disc and paraspinal tissues. It is reported in multiple studies that lumbarization and sacralization with resultant pseudoarthrosis between transverse process and sacrum alters the normal lumbar dynamics which causes stress on superjacent disc resulting in early disc degeneration. Subjacent disc is usually protected. Also there is associated facet joint arthropathy, muscle spasm and nerve root compression ${ }^{10,11}$.

Otani et al described association of lumbosacral transitional vertebra and disc degeneration in $17 \%$ of cases while in control group it is com-

Table-I: Crosstabulation of gender distribution and Castellvi type LSTV among the group with degenerative disc disease ( $\mathrm{n}=104)$.

\begin{tabular}{l|c|c|c|c}
\hline & $\begin{array}{c}\text { Type-1 LSTV with } \\
\text { disc degeneration }\end{array}$ & $\begin{array}{c}\text { Type-IIL STV with } \\
\text { disc degneration }\end{array}$ & $\begin{array}{c}\text { Type-III LSTV } \\
\text { with disc degeneration }\end{array}$ & $\begin{array}{c}\text { Type-IV LSTV } \\
\text { with disc degeneration }\end{array}$ \\
\hline \multirow{2}{*}{ Female } & $\begin{array}{c}6(5.7 \%) \\
p \text {-value }=0.09\end{array}$ & $\begin{array}{c}10(9.6 \%) \\
p \text {-value }=0.08\end{array}$ & $\begin{array}{c}39(37.5 \%) \\
p \text {-value }=0.006\end{array}$ & $\begin{array}{c}10(9.6 \%) \\
p \text {-value }=0.08\end{array}$ \\
\hline \multirow{2}{*}{ Male } & $\begin{array}{c}6(5.7 \%) \\
p \text {-value }=0.09\end{array}$ & $\begin{array}{c}22(21.1 \%) \\
p \text {-value }=0.06\end{array}$ & $\begin{array}{c}1(0.9 \%) \\
p \text {-value }=0.1\end{array}$ & $\begin{array}{c}10(9.6 \%) \\
p \text {-value }=0.08\end{array}$ \\
\hline
\end{tabular}

ponderance. Among the patients having degenerative disc disease were 59 females and 45 males and among group with no disc disease were 190 paratively less present in $11 \% 12$. In our study we only included patients with LSTV and tried to find out the frequency of disc degeneration 
among these patients and our study revealed that $26.6 \%$ patients had disc degeneration while $74.4 \%$ patients were not having disc degeneration, so approximately 1 in 4 patient with LSTV in our study had disc degeneration, though not majority of cases had disc changes but 1 in 4 patient with disc degeneration cannot be ignored altogether as etiological factor. Furthermore, this association cannot be denied due to the fact that we included only those cases after initial sampling who had no other etiological factor but LSTV.

Complete evaluation of LSTV and related discogenic disease needs multimodality approach and we used X-ray and MRI both in our study.

We further studied Castellvi types and frequency of disc degeneration and in our study type III was maximally associated with disc herniation, followed by type II, type IV and type I, table-I. In a study by Apazidis et al, commonly observed type was Castellvi type type-IA had prevalence of $14.7 \%^{13}$. Similarly a study by Nardo et al, type-I and type-II had highest frequency in $40 \%$ cases with LSTV 14 .

In almost all the literature related to degenerative disc disease associated with LSTV the affected disc in sacralization is L4-5 and L5-L6 in case of lumbarization. In our study also L4-5 and L5L6 disc showed degeneration in sacralization and lumbarization respectively. In studies by Luoma et al and Bron et al, L4-5 disc is the most commonly involved and they attributed it to the dynamic changes occurring at this level due to sacralized transitional vertebra ${ }^{15,16}$. Aihara et al had the same findings and in their study hypermobility and abnormal torque at this level is the likely cause ${ }^{17}$.

This study describes comparatively high frequency of disc disease among females however no statistically significant association was found but type-III LSTV has statistically significant association with female gender in our study. Our study showed the age of patients with disc degeneration was relatively higher between 24-40 years with the mean age $29.96 \pm 0.417$ years; $(95 \%$ CI 29.9 to 30). Comparatively patients having no degenerative disc disease were relatively young between 20-24 years with mean $22 \pm 1.5$ years (95\% CI 21.8 to 22.). A study conducted in India by Reddy Ravikanth and Pooja Majumdar mean age was $39 \pm 15$ years 7,18 . Gender distribution also showed female preponderance with 70 women and 59 men in this study.

\section{CONCLUSION}

Age related disc degeneration is commonly seen in middle age people but in younger age group in $2^{\text {nd }}$ and $3^{\text {rd }}$ decade it is observed frequently in those patients having lumbosacral transitional vertebra especially in the setting of no other associated traumatic or non-traumatic etiology. It is due to altered dynamics and prolonged stress because of pseudoarthrosis or complete fusion at lumbosacral junction which leads to early degenerative disc disease.

\section{CONFLICT OF INTEREST}

This study has no conflict of interest to be declared by any author.

\section{REFERENCES}

1. Jancuska JM, Spivak JM, Bendo JA. A review of symptomatic lumbosacral transitional vertebrae: Bertolotti's syndrome. Int J Spine Surg 2015; 9(1): 42.

2. Quinlan JF, Duke D, Eustace S. Bertolotti's syndrome. A cause of back pain in young people. J Bone Joint Surg Br 2006; 88(9): 1183-86.

3. Mahato NK. Redefining lumbosacral transitional vertebrae (LSTV) classification: Integrating the full spectrum of morphological alterations in a biomechanical continuum. Med Hypotheses 2013; 81(1): 76-81.

4. Chang I, Won Kim S, Gyue Kim J, Myung Lee S, Shin H. Decompressive L5 transverse processectomy for Bertolotti's syndrome: a preliminary study. Pain Physician 2017; 20(6): 923-32.

5. Neelakantan S, Anandarajan R, Shyam K, Philip B. Multi-modality imaging in Bertolotti's syndrome: An important cause of low back pain in young adults. Bio Med J Case Rep 2016; 2016: bcr2016217121.

6. Konin GP, Walz DM. Lumbosacral transitional vertebrae: Classification, imaging findings, and clinical relevance. AJNR Am J Neuroradiol 2010; 31(10): 1778-86.

7. Ravikanth R, Majumdar P. Bertolotti's syndrome in low backache population: classification and imaging findings. TZU Chi Med J 2019; 31(2): 90-95.

8. Hughes RJ, Saifuddin A. Imaging of lumbosacral transitional vertebrae. Clin Radiol 2004; 59(11): 984-91.

9. Kongsted E, Bunger C, Bindzus C. Symptomatic lumbosacral transitional vertebra: a review of the current literature and clinical outcomes following steroid injection or surgical intervention. Published online SICOT J 2017; 2017(3): 1-7.

10. Manmohan S, Dzulkarnain A, Nor-Azlin ZA, Bertolotti's syndrome: a commonly missed cause of back pain in young patients. Malays Fam Physician 2015; 10(2): 55-58. 
11. Rodríguez BM, Sánchez RF, Abellán ED, Parra JZ, Canovas CS, Sánchez MIC. Bertolotti syndrome: A little known cause of lowback pain in childhood. J Pediatr 2015; 166(1): 202.

12. Otani K, Konno S. Lumbosacral transitional vertebrae and nerve-root symptoms. J Bone Joint Surg Br 2001; 83(8): 1137-40.

13. Apazidis A, Ricart PA, Diefenbach CM, Spivak JM. The prevalence of transitional vertebrae in the lumbar spine. Spine J 2011; 11(9): 858-62.

14. Nardo L, Alizai H, Virayavanich W, Liu F, Hernandez A, Lynch JA, et al. Lumbosacral transitional vertebrae: Association with low back pain. Radiol 2012; 265(2): 497-503.

15. Luoma K, Vehmas T, Raininko R, Luukkonen R, Riihimaki H.
Lumbosacral transitional vertebra: relation to disc degeneration and low back pain. Spine 2004; 29(2): 200-05.

16. Bron JL, van Royen BJ, Wuisman PI. The clinical significance of lumbosacral transitional anomalies. Acta Orthop Belg 2007; 73(6): 687-95.

17. Aihara T, Takahashi K, Ogasawara A, Itadera E, Ono Y, Moriya $\mathrm{H}$. Intervertebral disc degeneration associated with lumbosacral transitional vertebrae: A clinical and anatomical study. J Bone Joint Surg Br 2005; 87(5): 687-91.

18. Dizdarevic I, Bishop M, Sgromolo N, Hammoud S, Atanda A. Approach to the pediatric athlete with back pain: More than just the pars. Phys Sports Med 2015; 43(4): 421-31. 